\title{
Health Economic Aspects
}

Michael Weißer, Hubertus Rosery, Tonio Schönfelder

5.1 Costs -106

5.1.1 Direct Costs - 106

5.1.2 Indirect Costs -112

5.1.3 Intangible Costs and Health Burden - 112

5.2 Financing, Remuneration and Regulations -114

References -118 


\section{Summary}

The costs incurred for knee and hip arthroplasty depend on the different type of treatments provided within the chain of medical care. Indirect costs of the disease, such as the incapacity to work resulting from the underlying diseases and intangible costs which cannot be evaluated in monetary terms, must also be taken into account. Patient care is financed through established remuneration systems. According to different publications, data extrapolations have shown that German statutory health insurances spent approximately 1.4 to 1.6 billion euros per year on hospital treatments for hip arthroplasty between 2003 and 2009. With regard to knee arthroplasty, expenditure for the same period was estimated at 1.0 to 1.3 billion euros per year. The direct costs for the associated inpatient stays are financed through case-based fees, which are in turn based on the actual average hospital costs. The most commonly remunerated case fees (hip arthroplasty/knee arthroplasty) have shown cost increases of a few percentage points over the last few years which are mainly due to the rising costs of personnel. In the two case-fee groups, implant costs constitute $21 \%$ of the total cost for hip treatments and $25 \%$ of the total cost for knee treatments. Particularly complicated cases such as infected hip endoprostheses are relatively more costly. With regard to indirect costs, the diagnosis »Osteoarthritis of hip « (ICD-10 M16) resulted in 2,585,157 days of incapacity to work amongst compulsory statutory health insurees (excluding pensioners) in 2011. For »Osteoarthritis of knee« (ICD-10 M17) the figure was almost double at $4,971,052$. Some patients who are in employment are unable to return to work despite having undergone a joint replacement and either have to change profession or accept a loss of income that includes social security contributions. Osteoarthritis, which is the most common reason for hip or knee replacements, is associated with a significant, increasing and in part immeasurable disease burden. International studies have demonstrated that the disease is accompanied by a high degree of suffering on the part of the patient as the large majority ( $70 \%$ or more) would be personally willing to finance the hip or knee arthroplasty at their own cost if the procedures were not included amongst those reimbursed by health insurance systems. Hospitals in Germany finance the costs of arthroplasty with one of several possible arthroplasty case fees selected according to the specific service provided and the circumstances of each case. The case fees are based on the average costs of a given treatment. The case fee figures in 2015, which were based on certain benchmarks, ranged between approximately 6,400 euros and 17,300 euros. However, case fees do not always seem to cover the hospital costs, particularly in the treatment of more complicated cases.

\subsection{Costs}

\subsubsection{Direct Costs}

Direct costs of treatment for patients who undergo knee or hip arthroplasty include those incurred prior to surgery, during inpatient stay and over the course of postoperative treatment.

The typical ideal treatment pathway for patients with osteoarthritis of the knee and the hip starts in an ambulatory setting with a consultation with a primary-care physician and continues with the referral to a practice-based specialist who subsequently refers the patient to hospital for surgery. After surgery, the patients undergo (subsequent) rehabilitation procedures and, if necessary, followup ambulatory care by the specialist physician (AQUA-Institut 2012).

Therefore, healthcare providers who are directly involved in the patient treatment, i.e. primary-care physicians, practice-based specialists, hospitals and rehabilitation establishments consequently incur healthcare expenses. Beyond this, physicians prescribing medication, therapeutic products or medical technical aids also add to further healthcare expenditure as do prescriptions for other care providers (for example, physiotherapists) in addition to material costs for equipment and consumables.

In 2008, the disease costs cited for the entire spectrum of osteoarthritis (ICD-10 M15M16) in Germany amounted to 7.62 billion euros. This total cost is distributed across various establishments within the chain of care (Rabenberg 2013) as presented in $\bullet$ Tab. 5.1.

Malzahn (2014) made various observations from an economic perspective with regard to the conservative and surgical treatment of patients who 


\begin{tabular}{|l|c|}
\hline \begin{tabular}{|l|l|} 
O Tab. 5.1 Osteoarthritis-related disease costs in \\
Germany in 2008, by type of medical institution
\end{tabular} \\
\hline Type of institution & $\begin{array}{c}\text { Total expenditure } \\
\text { in million } €\end{array}$ \\
\hline Ambulatory institutions & 2,547 \\
\hline Doctors' practices & 978 \\
\hline Pharmacies & 939 \\
\hline Ambulatory care & 515 \\
\hline Others & 660 \\
\hline Inpatient/day-care facilities & 4,284 \\
\hline Hospitals & 2,705 \\
\hline Preventive/rehabilitation facilities & 873 \\
\hline Inpatient care/day-care & 706 \\
\hline Other institutions & 790 \\
\hline Institutions in total & 7,620 \\
\hline Source: IGES - Destatis (2015) & \\
\hline
\end{tabular}

are of working age (20-59 years) who were suffering from osteoarthritis of the knee. His observations were based on the individual one-year periods before and after arthroplasty to treat osteoarthritis of the knee«. The data were obtained from services provided to male AOK insurees who were of working age. - Tab. 5.2 presents total expenditures for individual patients in the periods 12 months before to 12 months after surgery, divided into two age groups and according to conservative or surgical treatment. The data shows that the group of older patients constitutes the absolute majority of patients observed, but that individual patient expenditures are lower for the older age group than for the younger age group. This applies to both conservative and surgical treatment (Malzahn 2014).

The largest single expenditure item for individual patients, outside of expenses incurred in hospital, was expenditure on therapeutic products. It remains the largest single expenditure as long as the expenditure for medication is divided into costs that are strictly related to osteoarthritis only and costs that are potentially connected to osteoarthritis in a broader sense, as was done in the publication. These expenditures are presented in - Tab. 5.3.

-Tab. 5.4 presents expenditures for hospital services provided to the patient cohort observed. The implantation of the actual prosthesis is included in the 12 months after surgery expenditure period which is why preoperative hospital expenditure is the same for both considerations (with/without endoprosthetic replacement).

Endoprosthetic surgery costs have been estimated at 7,105.50 euros. This accounts for the difference observed between hospital expenditure with and without endoprosthetic replacements (costs per patient 12 months after surgery). The costs for the replacement itself are to be considered as an estimate based on the lowest determined value. This value is higher than the average expenditure for knee arthroplasty as it includes treatment costs related to osteoarthritis of the knee (main diagnosis M17) over a period of three months after surgery (Malzahn 2014).

- Tab. 5.2 Total individual patient expenditures for total knee arthroplasty (TKA) due to osteoarthritis of the knee

\begin{tabular}{|c|c|c|c|c|}
\hline \multirow[t]{4}{*}{ Patient age (years) } & \multirow[t]{4}{*}{ Case number } & \multicolumn{3}{|l|}{ Expenditure $(€)$} \\
\hline & & 12 months before surgery & \multicolumn{2}{|c|}{12 months after surgery } \\
\hline & & Conservative treatment & \multicolumn{2}{|l|}{ Surgery } \\
\hline & & & $\begin{array}{l}\text { Including TKA } \\
\text { expenditure }\end{array}$ & $\begin{array}{l}\text { Excluding TKA } \\
\text { expenditure }\end{array}$ \\
\hline $20-49$ & 452 & $1,249.34$ & $9,638.71$ & $2,533.21$ \\
\hline $50-59$ & 3,895 & 988.26 & $8,145.07$ & $1,039.57$ \\
\hline
\end{tabular}

Source: IGES - Mahlzahn (2014) 
Tab. 5.3 Expenditures for therapeutic products, contractual physician care and drugs for patients with osteoarthritis of the knee who undergo total knee arthroplasty (TKA)

\begin{tabular}{|l|l|l|}
\hline Patient age (years) & Expenditure 12 months before surgery $(€)$ & Expenditure 12 months after surgery $(€)$ \\
\hline Expenditure for therapeutic products & 378.97 \\
\hline $20-49$ & 125.25 & 395.57 \\
\hline $50-59$ & 133.38 & \\
\hline Expenditure for contractual physician care & 75.19 & 87.55 \\
\hline $20-49$ & 95.55 & 106.81 \\
\hline $50-59$ & 55.13 & 58.19 \\
\hline Expenditure for drugs I: strictly for osteoarthritis only & 65.09 \\
\hline $20-49$ & 65.91 & \\
\hline $50-59$ & 196.52 & 313.14 \\
\hline Expenditure for drugs II: potentially related to osteoarthritis & 100.45 \\
\hline 20-49 & 114.39 & \\
\hline $50-59$ & & \\
\hline Source: IGES - Mahlzahn $(2014)$ & \\
\hline
\end{tabular}

Tab. 5.4 Hospital expenditure for patients with osteoarthritis of the knee who undergo total knee arthroplasty (TKA)

\begin{tabular}{|l|l|l|}
\hline Patient age (years) & $\begin{array}{l}\text { Expenditure } 12 \text { months before surgery }(€) \\
\text { per patient }\end{array}$ & $\begin{array}{l}\text { Expenditure } 12 \text { months after surgery (€) } \\
\text { per patient }\end{array}$ \\
\hline \begin{tabular}{l|l|l|} 
Hospital expenditure \\
$20-49$
\end{tabular} & 797.28 & $8,800.86$ \\
\hline $50-59$ & 579.03 & $7,477.15$ \\
\hline Hospital expenditure excluding endoprosthetic replacement & \\
\hline $20-49$ & 797.28 & $1,695.36$ \\
\hline $50-59$ & 579.03 & 371.65 \\
\hline Source: IGES - Mahlzahn (2014) & \\
\hline
\end{tabular}

According to the SHI Barmer GEK (2010), extrapolations from the period between 2003 and 2009 showed that statutory health insurance funds in Germany spent approximately 1.4 to 1.6 billion euros per year on hospital treatment for hip arthroplasty. For knee arthroplasty, the amounts for the same period were estimated at 1.0 to 1.3 billion euros per year (Barmer GEK 2010).
The remuneration that a hospital receives for inpatient treatment cases constitutes the direct health insurance fund costs for the treatment case. The hospitals receive fees on a case-per-case basis (case fees) for individual inpatient stays for primary total arthroplasty and revision total arthroplasty/ revisions (the case fees are also labelled Diagnosis Related Groups (DRGs)). The case fees reflect the 
average costs of treatment during a patient's stay in hospital.

The most commonly remunerated endoprosthetic procedure on the hip is DRG I47B (revision or replacement of a hip joint without complicating diagnosis/without complicating surgery). With regard to knee arthroplasty, the most common DRG is I44B (implantation of a bicondylar endoprosthesis or other endoprosthesis implantation/revision on the knee joint) (InEK 2009), cf. • Tab. 5.5 and - Tab. 5.6.

As can be seen from the terms used to describe the DRGs, the fees usually cover several different types of interventions. Consequently, calculating the average costs of primary arthroplasty, revisions and/or revision hip or knee replacements separately is not possible. This is because the DRG system remunerates similar cases and treatments based on the average costs of different interventions.

The cost composition of an individual DRG is presented in - Tab. 5.5 and $\bullet$ Tab. 5.6 using DRG I47B (endoprosthetics hip joint) and DRG I44B (endoprosthetics knee joint) as examples. The German institute for hospital reimbursement »Institut für das Entgeltsystem im Krankenhaus (InEK) « collects the relevant cost data from several hundred German hospitals on an annual basis ( $\$ 17 \mathrm{~b}$ German Hospital Remuneration Act KHG (InEK 2014)). The calculations are defined by actual average cost data for specific cases in a particular year. The tables contain data from 2008 to 2013 illustrating changes in proportions of the different costs.

- Tab. 5.5 shows that medical personnel (cost type 1-3) account for the largest proportion of costs related to DRG I47B cases, i.e. the average hip replacement or revision case $(2,750.33$ euros in 2013, or just under $44 \%$ of the total amount). In contrast, implants show lower proportions of medical personnel costs at 1,329.94 euros or approximately $21 \%$ of the total amount. From 2009 to 2013, the costs for an average treatment case rose by approximately 325 euros, which was due to increasing staff costs in particular. Implant costs, however, have hardly changed.

A similar trend is presented in • Tab. 5.6. In 2013, the staff costs related to hospital treatment cases under DRG I44B (implantation of a bicondylar endoprosthesis or other endoprosthesis implan-

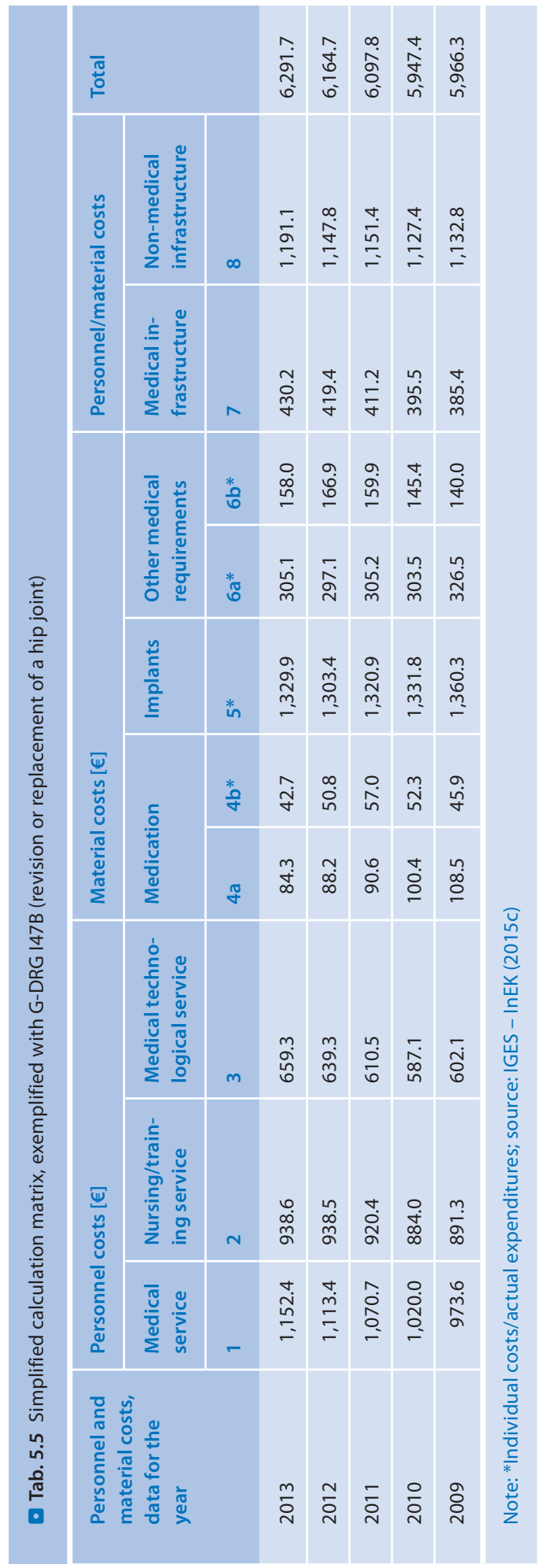






\begin{tabular}{|c|c|c|}
\hline Group & $\begin{array}{l}\text { Patient } \\
\text { number }\end{array}$ & $\begin{array}{l}\text { Costs per } \\
\text { patient }(€)\end{array}$ \\
\hline $\begin{array}{l}\text { Infected hip } \\
\text { endoprosthesis }\end{array}$ & 49 & $29,331.36$ \\
\hline Primary THA & 21 & $6,263.59$ \\
\hline
\end{tabular}

tation/revision on the knee joint) amounted to 2,887.37 euros (cost types 1-3), approximately $43 \%$ of the total amount. Implant costs amounted to $1,504.78$ euros or approximately $22 \%$ of the total amount. In these DRG cases, the costs also increased by approximately 315 euros from 2009 to 2013 . Although implant costs decreased during this period, staff costs in particular increased, as was the case for DRG I47B. Haenle et al. (2012) conducted a retrospective study on the costs of revision surgery due to periprosthetic infection after primary total hip arthroplasty. The study assessed a group of 49 patients who underwent revision (with different kinds of revision procedures) the different costs of which were compared to the costs and remuneration for 21 patients with primary total hip arthroplasty. All the patients were treated in the Rostock University Medical Center. The 49 patients with infected endoprostheses had an average length of stay of 52.7 days, of which 4.4 days were in intensive care. The average costs for both groups are shown in •Tab. 5.7 (Haenle et al. 2012).

This shows that revision total replacements with periprosthetic infection lead to costs that are several times higher than primary arthroplasty costs. The highest cost items of the surgery are presented in - Tab. 5.8 (Haenle et al. 2012).

The analysis is not representative for Germany as it was based on a small group of patients who were treated in a single center. However, the calculation does demonstrate the additional expenses for treating infected endoprostheses.

An additional German study including 114 patients assessed the surgery costs of hip revisions due to aseptic loosening of the endoprosthesis (one of 
- Tab. 5.8 Costs of primary THA and infected hip prosthesis

\begin{tabular}{|l|l|l|}
\hline Costs of & Primary THA & Infected hip prosthesis \\
\hline Implant & $€ 2,111.66(33.7 \%)$ & $€ 5,133.12(17.5 \%)$ \\
\hline Medical requirements & $€ 1,165.27(18.6 \%)$ & $€ 6,254.99(21.3 \%)$ \\
\hline Normal hospital ward & $€ 1,713.76(27.4 \%)$ & $€ 7,134.91(27.4 \%)$ \\
\hline Anesthesia & $€ 710.27(11.3 \%)$ & $€ 5,395.61(18.4 \%)$ \\
\hline Source: IGES - Haenle et al. (2012) & & \\
\hline
\end{tabular}

the most common reasons for revisions, $\triangleright$ Chapter 3.3) (Assmann et al. 2014). The study focused on the direct costs of the intervention and compared these with the respective DRG calculations. DRG calculations are maintained by the German Institute for Hospital Reimbursement »Institut für das Entgeltsystem im Krankenhaus (InEK) « using cost data from several hundred German hospitals ( $\bullet$ Chapter 5.2). An analysis published by Assmann et al. (2014) grouped the cost components into two cost items: the hospital ward costs and the actual surgery costs. - Tab. 5.9 illustrates a comparison between the average treatment costs of the study population and the calculated costs of the most common DRGs. It should be noted that the DRG characteristics and calculations are based on 2011 figures and specifications (Assmann et al. 2014).

The majority of revision replacements (98 of a total of 114 patients) were allocated to DRGs I46A (referred to in 2011 as "Change of prosthesis of the hip joint with very severe $\mathrm{CC}$ or with allogenic bone transplant «) and I46B (referred to in 2011 as "Change of prosthesis of the hip joint without very severe CC, without allogenic bone transplant«). The direct average costs in the study population were 4,380 euros which were below the calculated costs for the corresponding DRGs. The authors attribute this difference to indirect hospital costs (administrative costs, buildings, energy, etc.) (Assmann et al. 2014). As this study solely illustrates the cost structure of one individual hospital it cannot be considered representative for Germany as a whole.

A randomized controlled study conducted in Finland of patients who underwent TKA to determine whether delayed or untimely treatment leads to (additional) costs presents the following results (Tuominen et al. 2010). Over 400 osteoarthritis patients were randomly allocated either to a waiting list for surgery to take place within three months or, as is common in normal hospital routine, to a waiting list with a waiting period of longer than three months. The average waiting times were 94 days in one group and 239 days in the other. Statistically significant differences between the groups were identified for two aspects. In the group that had to wait longer for surgery, the health-related quality of life one year post-surgery was higher than in the other group. In contrast, the weekly cost of medication at the time of hospital admission was higher in the group that had shorter waiting periods. The authors discuss that the latter result could be due to the fact that patients within the shorter waiting period group had more severe pain at the time of inclusion in the study. No statistically significant differences with regard to the weekly cost of medication could be found at the time of the three month follow-up and one year after surgery (Tuominen et al. 2010).

In most cases of hip and knee arthroplasty patients undergo subsequent rehabilitation treatment (AHB) and some patients even receive medical rehabilitation care prior to surgery ( $\vee$ Chapter 3.4 ). The direct costs of rehabilitation should be added to the costs of additional ambulatory care and inpatient stays. However, as mentioned in Section 3.4., the data regarding rehabilitation are fragmented and limited. 




\subsubsection{Indirect Costs}

From a societal perspective, indirect costs arise as patients with osteoarthritis of the knee or hip arise are unable to work and hence lose years of employment.

In 2011, the diagnosis "Osteoarthritis of the hip « (ICD-10 M16) resulted in 2,585,157 days of incapacity to work amongst the compulsory statutory health insurees (excluding pensioners). For "Osteoarthritis of the knee« (ICD-10 M17), the number of days of incapacity to work was almost double at 4,971,052 days. In the same year, approximately 1,600 working people went into retirement due to a reduced capacity to work as a result of osteoarthritis of the hip and approximately 3,100 due to osteoarthritis of the knee. In 2011, these accounted for almost $80 \%$ of all people going into retirement because of osteoarthritis. The average age at the time of retirement was approximately 55 years for women and 56 years for men. The diseases osteoarthritis of the knee and osteoarthritis of the hip are therefore of great economic importance with regard to indirect costs (Rabenberg 2013).

This is further highlighted by an analysis of routine data by the German Statutory Pension Insurance. Even if patients can be reintegrated back into work after undergoing a joint replacement, it may result in their having to change profession or in a loss of income that includes social security contributions. The analysis shows that this is the case in $36.5 \%$ of all patients following total hip arthroplasty (Krischak et al. 2013).

\subsubsection{Intangible Costs and Health Burden}

Besides direct and indirect costs, patients are also subject to intangible costs.

II Intangible costs arise from incidents such pain and anxiety and cannot be directly calculated in terms of resource requirements or evaluated in monetary terms (IQWiG 2015).

Intangible costs are difficult to quantify and hence only very few studies on the subject exist. With regard to the underlying diagnosis ( $\triangleright$ Chapter 2 ) high 
intangible costs due to pain and anxiety before surgery can be expected on the part of patients. A number of international studies based on data collected on a patient's willingness to pay for treatment have been conducted. However, their validity for Germany is limited. Approaches that use the willingness to pay aim to assess intangible costs for avoiding disease, pain and anxiety in monetary measures.

An Australian study surveyed patients who had to undergo THA or TKA and their willingness to pay for treatment two to three years after the surgery. The patients were asked how much and whether they were willing to pay out of their own pocket for arthroplasty if the procedure was not included in the services provided by the healthcare system. $71 \%$ of THA patients were prepared to pay for the operation but $11 \%$ reported that they were not willing to do so. $25 \%$ of the patients stated they were willing to pay more than 15,000 Australian dollars, which was equivalent to the hospital costs for joint replacements at the time. With regard to TKA patients, $70 \%$ reported that they were willing to pay for the surgery, but $16 \%$ said they were not. $18 \%$ of the patients said they were willing to pay over 15,000 Australian dollars. Amongst the patients who were willing to pay for surgery in both groups (THA and TKA), the relative majority in each group were willing to pay up to 4,999 Australian dollars. The author's calculations illustrated that those patients who were more willing to pay achieved better outcomes after surgery with regard to both their general and disease-specific conditions (including pain, joint stiffness and physical function). According to the authors, other aspects besides the state of health also played a role in the willingness to pay for treatment. For TKA patients, the most important aspects included the patients « willingness to recommend the treatment, having private health insurance and lower WOMAC pain scores. For THA patients, the strongest predictor for the willingness to pay was income, followed by the pain classification in the WOMAC score (Cross et al. 2000).

A study of 105 patients with osteoarthritis of the knee conducted in a center in Singapore investigated the amounts participants were willing to pay for a hypothetical, complete cure of osteoarthritis without any side effects. The willingness to pay depended not only on the patients " income and employ- ment status but also on their general condition. A higher perceived state of health led to a lower willingness to pay (Xie et al. 2008).

Health-related factors that have a significant influence on the (hypothetical) willingness to pay for treatment of osteoarthritis of the knee, or for THA and TKA as alternative intangible cost variables, seem in particular to be pain and the patients' general state of health. In addition, (socio)economic factors also seem to play a role in the amount patients were willing to pay.

The quality-adjusted life year (QALY) concept is an approach that takes into account a patient's quality of life for cost evaluations. It measures the benefit of medical interventions or surgery in relation to the resulting prolongation of life and the quality of life gained by the patient (Schulenburg and Greiner 2007). To calculate this, the effect of surgery on the quality of life as well as on the prolongation of life must be identifiable. In this concept, one year of full health corresponds to a value of 1 (= optimum state of health) and death corresponds to a value of 0 (= worst state of health) (Phillips and Thompson 2009, Schulenburg and Greiner 2007). For example, surgery that prolongs the remaining lifetime of a patient by 10 years with impaired health of 0.75 would result in 7.5 ( $10 \times 0.75)$ quality-adjusted life years or QUALYs.

A study carried out from the perspective of the German SHI system by Mujica-Mota et al., analyzed both the average and incremental costs per QALY of patients who were either treated conservatively (without surgery) or who underwent THA (MujicaMota et al. 2015). The analysis demonstrated that the costs for both forms of treatment were comparable. For 55-year-old patients, non-surgical treatment leads to costs of approximately 27,300 euros for their remaining lifetime. With regard to THA, timely and delayed surgeries were analyzed separately. The median period between both operations was 11 years. Delayed THA resulted in costs of 26,800 euros and timely THA resulted in costs of 28,600 euros. However, marked differences were found between the treatment procedures with regard to QALYs. Non-surgical treatment amounted to 10.3 QALYs, and significantly higher values of 18.8 QALYs were established for delayed THA and 20.7 QALYs for timely THA. When the incremental 
costs per QALY (discounted at $5 \%$ ) were investigated for both types of surgical treatment, timely THA was shown to be more cost-effective than delayed THA by approximately 1,000 euros for women treated at the age of 55 and 1,250 euros for women treated at the age of 65 and 1,100 euros or 1,900 euros respectively for men (Mujica-Mota et al. 2015).

Chronic joint diseases are considered to be the most frequent cause of disability in the USA. According to WHO calculations, they are the fourth most common cause of years lived with a disability (YLD) worldwide (Merx et al. 2007).

The Global Burden of Disease study compared 291 diseases based on the causes of disabilities measured in YLD and ranked hip and knee osteoarthritis $11^{\text {th }}$ amongst diseases assessed worldwide in 2010. Following diabetes and falls, hip and knee osteoarthritis are therefore amongst the most common diseases that lead to disability. In 1990, osteoarthritis was ranked $15^{\text {th }}$ amongst diseases assessed. According to calculations in this study, the YLDs for osteoarthritis of the hip and knee have risen globally from 10.5 million in 1990 to 17.1 million in 2010 (Cross et al. 2014).

For the entire disease burden, calculated as disability-adjusted life years (DALY), osteoarthritis of the hip and the knee ranked $38^{\text {th }}$ in 2010 , following cardiovascular diseases and epilepsy, amongst others. Since 1990, the number of DALYs has been increasing with osteoarthritis of the hip and the knee ranking $48^{\text {th }}$, resulting in an increase in their disease burden as was also observed for YALYs. In 1990 , they accounted for $0.42 \%$ of the total DALYs calculated. In 2010, this proportion rose to $0.69 \%$ (Cross et al. 2014).

Joint diseases, particularly osteoarthritis which is the most common reason for requiring a joint replacement, are therefore accompanied by a significant, increasing and sometimes immeasurable disease burden.

\subsection{Financing, Remuneration and Regulations}

Statutory health insurance funds in Germany cover ambulatory services provided by physicians who are members of statutory health insurance physicians" associations. These services are remunerated based on the uniform value scale "Einheitlicher Bewertungsmaßstab (EBM)«. The physician is remunerated directly for services that are listed in the EBM without the patient having to pay for the services themselves.

Regarding private health insurance, the physician invoices the patient based on the physicians' fee catalog »Gebührenordnung für Ärzte (GOÄ)«. The patient pays for the service and the costs are subsequently reimbursed by the private health insurance fund.

The costs of medication, therapeutic products and medical technical aids prescribed by the physician are covered by the payers, provided they are approved for reimbursement.

For both statutory and private health insurances there may be services that have not been approved by the payers and which patients consequently have to cover themselves without being reimbursed. Under the statutory health insurance system, individual health services that are paid for privately by the patient are termed »Individuelle Gesundheitsleistungen ( $\mathrm{IGeL})$ «.

Immediate and running costs of medically required hospital services are covered by statutory and private health insurances and remunerated according to the German case-based payment system »German Diagnosis Related Groups, (G-DRG) «. The G-DRG system is developed further every year by the InEK. Chapter 5.1.1 presents typical DRGs for hip and knee replacements and the corresponding benchmarks for 2015. It also illustrates how a DRG is calculated. The most common case rates related to hip arthroplasty, according to the available relevant data (data publication according to $\$ 21 \mathrm{Hospi-}$ tal Remuneration Act), are listed in - Tab. 5.10 and those related to knee arthroplasty are listed in $\bullet$ Tab. 5.11. The tables illustrate the levels of remuneration for each flat rate as a monetary benchmark for patients with normal lengths of stays in 2015 . They also show the case numbers of patients with normal lengths of stay recorded in 2013. In some federal states, the amount reimbursed may deviate from the benchmarks presented.

An additional DRG which is not listed in the tables as it is attributable to both hip and knee ar- 
Tab. 5.10 Hospital case fees for hip arthroplasty, main department (2015)

\begin{tabular}{|c|c|c|c|}
\hline DRG & Text & $\begin{array}{l}\text { Case fee } \\
\text { (benchmark, } \\
€)^{*}\end{array}$ & $\begin{array}{l}\text { Registered patients with } \\
\text { normal lengths of stay } \\
\text { main department } 2013\end{array}$ \\
\hline $103 \mathrm{~A}$ & $\begin{array}{l}\text { Revision or replacement of the hip joint with complicating } \\
\text { diagnosis or arthrodesis or age }<16 \text { years or bilateral surgery } \\
\text { or several major procedures on the joints of the lower extrem- } \\
\text { ities with complicated procedure, with major CC or multi- } \\
\text { stage replacement or surgery in several regions }\end{array}$ & $17,280.46$ & 1,835 \\
\hline I03B & $\begin{array}{l}\text { Revision or replacement of the hip joint with complicating } \\
\text { diagnosis or arthrodesis or age }<16 \text { years or bilateral surgery } \\
\text { or several major procedures on the joints of the lower extrem- } \\
\text { ities with complicated procedure, without major CC, without } \\
\text { multi-stage replacement, without surgery in several regions }\end{array}$ & $12,049.15$ & 4,919 \\
\hline $105 \mathrm{~A}$ & $\begin{array}{l}\text { Revision or replacement of the hip joint without complicating } \\
\text { diagnosis, without arthrodesis, without complex surgery, with } \\
\text { major CC }\end{array}$ & $10,129.81$ & 6,773 \\
\hline $146 \mathrm{~A}$ & $\begin{array}{l}\text { Revision replacement hip joint prosthesis with major CC or } \\
\text { surgery in several regions }\end{array}$ & $17,089.82$ & 1,247 \\
\hline 146B & $\begin{array}{l}\text { Revision replacement hip joint prosthesis without major CC, } \\
\text { without surgery in several regions }\end{array}$ & $9,105.52$ & 14,188 \\
\hline $147 \mathrm{~A}$ & $\begin{array}{l}\text { Revision or replacement of the hip joint without complicating } \\
\text { diagnosis, without arthrodesis, without major CC, age }>15 \\
\text { years, with complicating surgery or implantation/revision } \\
\text { replacement of a radial head prosthesis or change of inlay of } \\
\text { the hip }\end{array}$ & $7,861.51$ & 10,317 \\
\hline 147B & $\begin{array}{l}\text { Revision or replacement of the hip joint without complicating } \\
\text { diagnosis, without arthrodesis, without major CC, age }>15 \\
\text { years, without complicating surgery }\end{array}$ & $7,237.9$ & 147,861 \\
\hline
\end{tabular}

* Assuming a nationwide base rate of 3231.20 euros in 2015; abbreviation: CC = complications or comorbidities, source: IGES calculations based on InEK data (2015a)

throplasty is DRG I36Z (bilateral implantation or revision hip or knee replacement). In 2013, approximately 800 patients with normal lengths of stay in Germany were allocated to this DRG. Similar to the calculations in - Tab. 5.10 and - Tab. 5.11, the benchmark value for this was 11,978.06 euros in 2015 (InEK 2015a).

Usually, the hospitals are required to cover their own costs based on these case rates. For the health insurance funds these constitute the direct costs of the relevant treatment cases.

Two main further remuneration pathways exist for costly treatments, which can be applied in addition to the relevant DRG case rate. Both options are defined by the InEK, as are the case rates themselves.

Additional funding for innovations is available under new examination and treatment methods »Neue Untersuchungs- und Behandlungsmethoden (NUB)'. Hospitals can submit NUB applications to the InEK DRG institute once a year. The InEK subsequently determines whether the prerequisites for temporary additional remuneration (NUB) for the individual hospital are fulfilled. If the NUB application is approved, the hospital enters into negotiations with the payers during the course of its overall budget negotiations. Negotiations are based on the number of treatments and the remuneration 
- Tab. 5.11 Hospital case fees for knee arthroplasty, main department (2015). IGES calculations based on InEK data (2015a)

\begin{tabular}{|c|c|c|c|}
\hline DRG & Text & $\begin{array}{l}\text { Case rate } \\
\text { (benchmark, } \\
€)^{*}\end{array}$ & $\begin{array}{l}\text { Registered patients with } \\
\text { normal lengths of stay } \\
\text { main department } 2013\end{array}$ \\
\hline $104 Z$ & $\begin{array}{l}\text { Implantation, replacement or removal of a knee endopros- } \\
\text { thesis with complicating diagnosis or arthrodesis }\end{array}$ & $11,451.37$ & 4,111 \\
\hline $143 \mathrm{~A}$ & $\begin{array}{l}\text { Implantation or replacement of specific knee or elbow endo- } \\
\text { prostheses or replacement of shoulder or ankle prostheses, } \\
\text { with major CC }\end{array}$ & $15,836.11$ & 1,014 \\
\hline 143B & $\begin{array}{l}\text { Implantation or replacement of specific knee or elbow endo- } \\
\text { prostheses or replacement of shoulder or ankle prostheses } \\
\text { without major CC }\end{array}$ & $10,297.83$ & 11,075 \\
\hline 144A & $\begin{array}{l}\text { Implantation of a bicondylar endoprosthesis or other endo- } \\
\text { prosthesis implantation/revision on the knee joint, with } \\
\text { major CC or correction of a rib cage deformity }\end{array}$ & $11,121.79$ & 1,314 \\
\hline 144B & $\begin{array}{l}\text { Implantation of a bicondylar endoprosthesis or other endo- } \\
\text { prosthesis implantation/revision on the knee joint, without } \\
\text { major CC or without correction of a rib cage deformity }\end{array}$ & $7,764.57$ & 103,628 \\
\hline 144C & Various types of endoprosthesic surgery on the knee joint & $6,407.47$ & 17,875 \\
\hline
\end{tabular}

amounts ( $\$ 6$ Section 2 Hospital Remuneration Act (SVR Gesundheit 2014)). Individual hospital negotiations regarding implantable endoprostheses for "(total) temporomandibular joint replacements" and »expandable endoprostheses « were granted by the InEK for the year 2015 (InEK 2015b).

Besides the NUB process, there is also the option of negotiating so-called additional remunerations (Zusatzentgelte (ZE)) in addition to the DRG case rate (cf. $\$ 7$ Hospital Remuneration Act (KHG)). These additional remunerations are not restricted to innovations (SVR Gesundheit 2014). In 2015, there were a total of 170 additional remunerations which are partly negotiable by individual hospitals. Regarding replacement surgery, additional remunerations for modular endoprostheses (ZE 2015-25, OPS 5-829.k, OPS 5-829.m) for individual hospitals can be agreed upon between the hospitals and the health insurance funds (InEK 2015a).

Figure 5.1 illustrates a total cost comparison of unilateral primary hip replacement in nine European countries and shows that the remuneration was higher than the calculated costs for all countries except for Poland. The remuneration for Spain could not be determined due to the specifics of the healthcare system. It can also be observed that the level of remuneration in Germany was not the highest amongst the countries listed (Stargardt 2008).

Although the analysis for Germany indicates a financial gain for hospitals performing the surgery, the actual situation can differ significantly depending on the treatment case.

Haenle et al. 2012 reviewed not only the costs of revision procedures in comparison to primary THA but also the corresponding excesses or shortfalls in payments in the DRG remuneration system. The average costs, DRG remuneration and the excess or shortfalls in payments for both groups are presented in - Tab. 5.12 (Haenle et al. 2012).

It becomes apparent that the treatment of infected hip endoprostheses resulted in costs of almost 30,000 euros and a deficit of approximately 12,700 euros. Consequently, cases in treating hospitals were underfinanced. This demonstrates the 


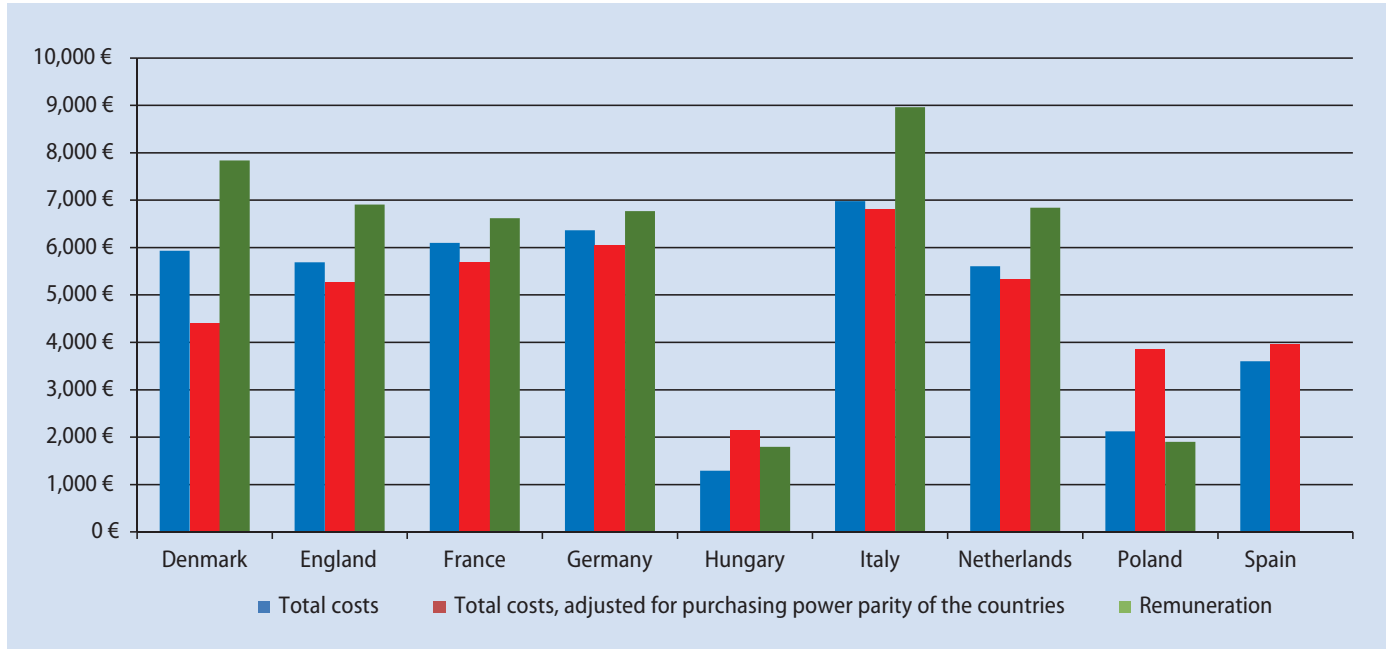

- Fig. 5.1 Costs and remuneration of primary hip arthroplasty in nine European countries in 2005. (Source: IGES Stargardt 2008)

- Tab. 5.12 Deficit/surplus in the DRG system with regard to infected hip endoprostheses

\begin{tabular}{|l|l|l|l|l|}
\hline Group & $\begin{array}{l}\text { Number of } \\
\text { patients }\end{array}$ & $\begin{array}{l}\text { Costs per } \\
\text { patient }(€)\end{array}$ & $\begin{array}{l}\text { DRG } \\
\text { remuneration }(€)\end{array}$ & $\begin{array}{l}\text { Excess payment } \\
\text { or shortfalls }(€)\end{array}$ \\
\hline Infected hip prosthesis & 49 & $29,331.36$ & $16,645.76$ & $-12,685.60$ \\
\hline Primary total hip arthroplasty & 21 & $6,263.59$ & $7,045.00$ & 781.41 \\
\hline
\end{tabular}

economic challenge hospitals are faced with in such treatment cases, and they have to compensate the losses through gains made via other types of treatment.

A distinctive situation exists related to $\mathrm{SHI}$ financing. The so-called health fund "Gesundheitsfonds « was introduced on 1 January, 2009. Statutory health insurance funds receive the same amount (basic rate) for every insuree and additional or reduced amounts adjusted according to age, sex and risk (KV Berlin 2007). The morbidity oriented risk structure adjustment scheme (Morbi-RSA) takes into account the health status of insurees with regard to funding (Jahn et al. 2012). The additional remuneration for morbidity is based on 80 costly, chronic and severe diseases. "Osteoarthritis of the large joints « is included amongst the diseases listed by the German Federal Insurance Office (Bundes- versicherungsamt) which also covers osteoarthritis of the knee and the hip (Bundesversicherungsamt 2014).

Through the Morbi-RSA, health insurance funds that include older and more sickly insurees receive higher funds than those that include many healthier or young insurees. This assures compensation in accordance with the SHI's solidarity code, and consequently health insurance funds do not have the economic incentive to specifically acquire young and healthy patients as members (Bundesversicherungsamt 2008). As a result, standardized additional remunerations can be claimed for every insuree suffering from one of the 80 diseases. If during a patient's stay in hospital any of the relevant diseases are diagnosed, the additional remuneration is immediately paid to the patient's health insurance fund. If the diagnosis is made during ambulatory 
treatment, the additional remuneration is only paid in the following quarter once the diagnosis has been confirmed (DIMDI 2015).

Remuneration for rehabilitation services, which play a particular role following acute-care in hospital, is paid based on a per diem rate or case fee rate. Per diem rates tend to be applied for remuneration by the German Statutory Pension Insurance funding bodies and case rates by the statutory health in- surance. The degrees of severity of the cases are not differentiated in the case rates. Consequently, the financial risk of treating patients with severe cases lies with the care providers and not the payers. The case fees cover all costs, including investment costs. There is "hardly any representative data " with regard to the case rate amounts (SVR Gesundheit 2014).

Open Access This chapter is published under the Creative Commons Attribution NonCommercial 4.0 International license (http://creativecommons.org/licenses/by-nc/4.0/deed.de) which grants you the right to use, copy, edit, share and reproduce this chapter in any medium and format, provided that you duly mention the original author(s) and the source, include a link to the Creative Commons license and indicate whether you have made any changes.

The Creative Commons license referred to also applies to any illustrations and other third party material unless the legend or the reference to the source states otherwise. If any such third party material is not licensed under the above-mentioned Creative Commons license, any copying, editing or public reproduction is only permitted with the prior approval of the copyright holder or on the basis of the relevant legal regulations.

\section{References}

AQUA-Institut (2012): Knieendoprothesenversorgung. Abschlussbericht. Göttingen: AQUA - Institut für angewandte Qualitätsförderung und Forschung im Gesundheitswesen $\mathrm{GmbH}$.

Assmann G, Kasch R, Hofer A, Schulz AP, Kayser R, Lahm A, Merk H \& Flessa S (2014): An economic analysis of aseptic revision hip arthroplasty: calculation of partial hospital costs in relation to reimbursement. Archives of orthopaedic and trauma surgery 134(3), 413-420. DOI: 10.1007/s00402-014-1920-0.

BARMER GEK Report Krankenhaus 2010. Schwerpunktthema: Trends in der Endoprothetik des Hüft- und Kniegelenks. Schriftenreihe zur Gesundheitsanalyse, Band 3. St. Augustin: Asgard-Verlag. ISBN: 978-537-44103-4.

Bundesversicherungsamt (2008): So funktioniert der neue Risikostrukturausgleich im Gesundheitsfonds 2015/10/29/. www.bundesversicherungsamt.de/file admin/redaktion/Risikostrukturausgleich/Wie_funktioniert_Morbi_RSA.pdf [accessed: 03 November 2015].

Bundesversicherungsamt (2014): Bekanntgabe der für das Ausgleichsjahr 2015 zu berücksichtigenden Krankheiten und Diagnosen nach § 31 Abs. 2 RSAV.

Cross MJ, March LM, Lapsley HM, Tribe KL, Brnabic AJ, Courtenay BG \& Brooks PM (2000): Determinants of willingness to pay for hip and knee joint replacement surgery for osteoarthritis. Rheumatology (Oxford) 39(11), 12421248. ISSN: 1462-0324.
Destatis (2015): Krankheitskosten. Wiesbaden: Statistisches Bundesamt. https://www.destatis.de/DE/ZahlenFakten/ GesellschaftStaat/Gesundheit/Krankheitskosten/Krankheitskosten.html\#Tabellen [accessed: 11 November 2015].

DIMDI (2015): Morbi-RSA und Gesundheitsfonds. 2015/08/13/. Deutsches Institut für Medizinische Dokumentation und Information. https://www.dimdi.de/static/de/klassi/ icd-10-gm/anwendung/zweck/morbi-rsa/index.htm [accessed: 11 November 2015].

Haenle M, Skripitz C, Mittelmeier W \& Skripitz R (2012): [Economic impact of infected total hip arthroplasty in the German diagnosis-related groups system]. Der Orthopäde 41(6), 467-476. DOI: 10.1007/s00132-0121939-2.

InEK (2009): Krankenhausentgeltgesetz - KHEntgG. http:// www.g-drg.de/cms/Rechtsgrundlagen/Gesetze_und_ Verordnungen/Krankenhausentgeltgesetz_KHEntgG [accessed: 10 November 2015].

InEK (2014): Krankenhäuser mit einer Kalkulationsvereinbarung für DRG/PEPP oder Investitionskosten. Information correct as of: 22 July 2014. Siegburg. http://www.g-drg. $\mathrm{de} / \mathrm{cms} /$ Kalkulation2 [accessed: 10 November 2015].

InEK (2015a): Fallpauschalen-Katalog 2015. http://www.g-drg. de/cms/G-DRG-System_2015/Fallpauschalen-Katalog/ Fallpauschalen-Katalog_2015 [accessed: 10 November 2015].

InEK (2015b): Informationen nach § 6 Abs. 2 KHEntgG für 2015: Neue Untersuchungs- und Behandlungsmethoden. http://www.g-drg.de/cms/G-DRG-System_2015/Neue_ 
Untersuchungs-_und_Behandlungsmethoden_NUB/ Aufstellung_der_Informationen_nach_6_Abs._2_KH EntgG_fuer_2015 [accessed: 10 November 2015]. InEK (2015c): Report-Browser 2013/2015. http://www.g-drg. de/cms/G-DRG-System_2015/Abschlussbericht_zur_ Weiterentwicklung_des_G-DRG-Systems_und_Report_ Browser/ Report-Browser_2013_2015 [accessed: 10 November 2015].

IQWiG (2015): Allgemeine Methoden: Version 4.2 vom 22.04.2015. Köln: Institut für Qualität und Wirtschaftlichkeit im Gesundheitswesen. ISBN: 978-3-9815265-1-6.

Jahn R, Schillo S \& Wasem J (2012): Morbiditätsorientierter Risikostrukturausgleich - Wirkungen und Nebenwirkungen. Bundesgesundheitsblatt Gesundheitsforschung. Gesundheitsschutz. 55(5), 624-632. DOI: 10.1007/ s00103012-1470-y.

Krischak G, Kaluscha R, Kraus M, Tepohl L \& Nusser M (2013): Rückkehr in das Erwerbsleben nach Hüfttotalendoprothese. Unfallchirurg 116(8), 755-759. DOI: 10.1007/ s00113-013-2424-z.

KV Berlin (2007): GKV-WSG: Gesundheitsfonds. 2015/08/13/. https://www.kvberlin.de/20praxis/70themen/gesundheitsreform/gesundheitsfonds/ [accessed: 04 November 2015].

Malzahn J (2014): [Conservative and operative treatment of working age patients with gonarthritis. Economic considerations]. Der Orthopäde 43(6), 503-506, 508-510. DOI: 10.1007/s00132-014-2295-1.

Merx H, Dreinhofer KE \& Gunther KP (2007): [Socioeconomic relevance of osteoarthritis in Germany]. Zeitschrift fur Orthopadie und Unfallchirurgie 145(4), 421-429. DOI: 10.1055/s-2007-965552.

Mujica-Mota RE, Watson L \& Tarricone R (2015): Kosten-/ Nutzenanalyse von rechtzeitiger vs. verzögerter primärer Hüft-Totalendoprothetik in Deutschland. [Poster].

Phillips C \& Thompson G (2009): What is a QALY? What is...? series. Hayward Medical Communication.

Rabenberg M (2013): Arthrose. Gesundheitsberichterstattung des Bundes. Heft 54. Berlin: Robert Koch-Institut, Statistisches Bundesamt. ISBN: 978-3-89606-219-2.

Schulenburg, J.M. von der, \& Greiner W (2007): Gesundheitsökonomik. 2. Auflage. Tübingen: Mohr Siebeck. ISBN: 978-3161490606.

Stargardt T (2008): Health service costs in Europe: cost and reimbursement of primary hip replacement in nine countries. Health economics 17( 1 Suppl), S9-20. DOI: 10.1002/hec.1328.

SVR Gesundheit (2014): Bedarfsgerechte Versorgung - Perspektiven für ländliche Regionen und ausgewählte Leistungsbereiche: Gutachten 2014. Sachverständigenrat zur Begutachtung der Entwicklung im Gesundheitswesen (Hrsg.).
Tuominen U, Sintonen H, Hirvonen J, Seitsalo S, Paavolainen P, Lehto M, Hietaniemi K \& Blom M (2010): Is LongerWaiting Time for Total Knee Replacement Associated with Health Outcomes and Medication Costs? Randomized Clinical Trial. Value in Health 13(8), 998-1004. DOI: 10983015/10/998.

Xie F, Thumboo J, Fong K-J, Lo N-N, Yeo S-J, Yang K-Y \& Li S-C (2008): A Study on Indirect and Intangible Costs for Patients with Knee Osteoarthritis in Singapore. Value in Health 11(Supplement 1), S84-S90. 